\title{
Urban-rural disparity in the relationship between ambient air pollution and preterm birth
}

Long $\mathrm{Li}^{1}$, Jing Ma ${ }^{1 *} \mathbb{D}$, Yang Cheng ${ }^{1}$, Ling Feng ${ }^{2}$, Shaoshuai Wang ${ }^{2}$, Xiao Yun ${ }^{3}$ and Shu Tao ${ }^{3}$

\begin{abstract}
Background: Some studies have reported that air pollution exposure can have adverse effects on pregnancy outcomes. However, the disparity between urban and rural areas in the risk of preterm birth (PTB) has yet to be elucidated. Considering geographic contexts as homogeneous or ignoring urban-rural differences cannot accurately reveal the disparities in the health effects of air pollution under different geographic contexts. The aims of this study were to examine the disparities in the risks of PTB in three different regions and five urban-rural types and to investigate the extent to which fine particulate matter $\left(\mathrm{PM}_{2.5}\right)$ exposure during the entire pregnancy can explain the variations.

Methods: We collected data on 429,865 singleton newborns born in 2014 in Hubei Province, China, and divided Hubei Province into three regions. Spatial correlation methods were employed to measure the associations between the rate of PTB and air pollution using average annual indexes for the entire province and regions. A series of multilevel logistic models were conducted to examine disparities in the risks of PTB with decreases in urbanity and the effects of air pollution exposure on the occurrence of preterm births.

Results: The $\mathrm{PM}_{2.5}$ concentration was significantly different across the regions. The eastern region had the most wide-ranged and serious level of pollution, whereas the levels in the middle and western regions weakened. The odds of PTB and air pollution exhibited a positive spatial correlation for the entire province and in the east (BiMoran's $I=0.106$ and 0.697 , respectively). Significant urban-rural disparities in the risks of PTB were noted in the east and middle regions, and the mean $\mathrm{PM}_{2.5}$ exposure during the entire pregnancy was positively associated with PTB risk. However, in the west, the results showed weak differences in the risks of PTB among the five urban-rural types and an insignificant effect of $\mathrm{PM}_{2.5}$ exposure. The direction of the effect of district/county-level income on PTB varied by region.
\end{abstract}

Conclusions: This study finds that air pollution exposure and PTB have significant and positive spatial relationships in areas with a serious air pollution burden. The risks of PTB in three regions of Hubei Province follow the same W-shaped pattern as urbanity decreases and rurality increases. High levels of air pollution exposure may be an important disadvantage for urban pregnant women in this setting.

Keywords: Air pollution exposure, Preterm birth, Urban-rural disparity, Spatial correlation, Multilevel logistic model

\footnotetext{
*Correspondence: majingbnu@163.com

${ }^{1}$ Beijing Key Laboratory for Remote Sensing of Environment and Digital

Cities, Faculty of Geographical Science, Beijing Normal University, Beijing 100875, China

Full list of author information is available at the end of the article
}

\section{Background}

Fine particulate matter (with an aerodynamic diameter $\leq 2.5 \mu \mathrm{m}, \mathrm{PM}_{2.5}$ ) has become a main pollutant, and its relationship with human health has attracted great attention worldwide [1, 2]. With potential biological 
mechanisms related to inflammation and oxidative stress [3-5], $\mathrm{PM}_{25}$ can induce cardiovascular disease and respiratory disease [6-10], and increase the mortality rate $[11,12]$. Moreover, $\mathrm{PM}_{2.5}$ can prevent people from engaging in outdoor physical activities $[13,14]$ and has adverse effect on mental health, such as depression and anxiety [15-17].

The relationship between air pollution and delivery outcomes has become an important topic. Gestational week and birth weight are important predictors of infant morbidity and mortality [18-20]. Considerable research has explored the relationships between maternal air pollution exposure and various adverse outcomes, such as preterm birth (PTB), low birth weight (LBW), and small for gestational age (SGA). However, the results are inconclusive. While some studies showed that long-term or short-term maternal exposure during pregnancy had positive influences on adverse delivery outcomes $[5,21-$ 25], other studies found insignificant relationships [26] or even negative associations [27].

In addition to differences in methods [28, 29], the inconsistent results are also related to spatial landscape heterogeneity. Past cross-country or regional studies revealed spatial variations in exposure-health relationships [30, 31]. Landscape heterogeneity refers to the differences in certain characteristics of study areas, such as lifestyles, socioeconomic status (SES) and ecological environment, and these characteristics could mediate the relationship between pollution exposure and birth outcomes. Some research has suggested the notion of "double jeopardy", wherein the effect of the environment on health is greater in poor areas [32,33]. To make matters more complicated, the economy-emission relationship based on the environmental Kuznets hypothesis potentially exhibits an inverted U-shaped pattern [34]; thus, the impacts of income increases on health are not always positive.

The introduction of urban-rural location types could account for different economy-environment contexts. Compared with their urban counterparts, rural residents generally have disadvantaged SES, low nutritional status and less convenient access to medical services [35-38]. Some research showed that urban residents have better physical health than rural people [39, 40], while other research found non-significant distinctions [41]. Urbanrural disparities in environment-health relationships have been examined in very few studies [42, 43]. For instance, a recent study found that rural mortality was more sensitive to adverse temperature conditions than urban mortality [42]. Moreover, some research further indicated that health status did not change monotonically along the urban-rural continuum but more likely followed an inverted U or J-shape [44-46]. In terms of birth outcomes, Larson et al. found that crude rates of LBW in non-metro areas were lower than those in metropolitan areas in the US [47], while some other studies reported that pregnant women in rural areas adjacent to urban areas (or suburban areas) had better birth outcomes than both remote rural and urban counterparts $[48,49]$. By and large, the urban-rural disparity in the relationship between air pollution exposure and PTB has yet to be elucidated. In most prior studies, the urban-rural dichotomy assumed that one was superior to the other, ignoring the heterogeneity among metropolis, small cities, large towns, and rural areas, which could greatly differ in air quality, SES and health. Thus, a finer classification of urban-rural areas should be made in research on the relationships between PTB and environmental pollution.

This study attempts to investigate the air pollution-PTB association with a finer urban-rural classification using the case of Hubei Province, China. First, we investigated whether exposure to $\mathrm{PM}_{2.5}$ during the entire pregnancy significantly increased the risk of PTB. Second, we examined the disparities in the risks of PTB among various urban-rural continua and how air pollution exposure explained these variations. To the best of our knowledge, this is the first study that examines whether and to what extent $\mathrm{PM}_{2.5}$ exposure can explain the PTB risks with a finer-scale analysis of both urban-rural and regional disparities. This study contributes to the environmental health literature worldwide and provides a better understanding of the urban-rural disparity in the relationships between ambient air pollution exposure and PTB, particularly in developing countries, where such research has been very scarce to date.

\section{Study area}

Figure 1 shows the location of Hubei Province, which includes 17 prefecture-level cities, and each city consists of one or more districts and counties. The total area of the province is approximately $185,900 \mathrm{~km}^{2}$, and the population was 58.16 million by the end of 2014. Regarding natural conditions, mountainous regions account for $56 \%$ of the province [50] and are especially concentrated in the west, which partly restricts the development of urbanization in these areas and greatly affects the population and economic distribution of the province.

\section{Data}

\section{Neonatal and maternal clinical data}

In the analysis, the birth records of newborns and information on pregnant women were collected from the Health Commission of Hubei Province, and data from a total of 557,243 newborns in 2014 were obtained. The dataset records the maternal residence, hospital of delivery, individual and household socio-economic 


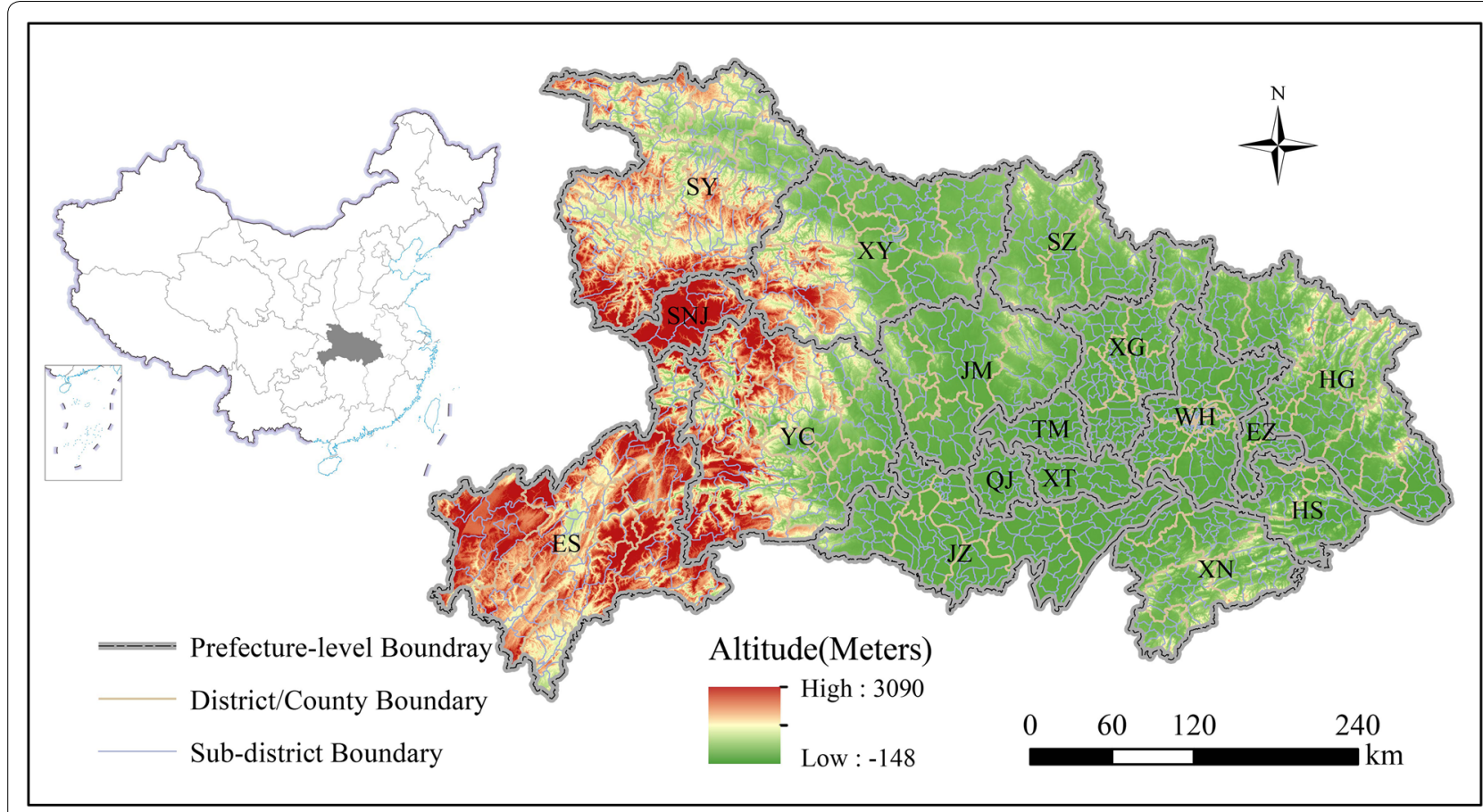

Fig. 1 Location of Hubei Province and its terrain and administrative division

information, physical examinations during pregnancy, neonatal and maternal physiological characteristics at the time of delivery, and so on. We geocoded each pregnant woman's residence location at the sub-district level, and 485,306 newborns with complete maternal residence information were retained. For each newborn, we collected considerable information on his/her mother, such as age, race/nationality, educational level, pregnancy test, conception and labour date. Neonatal characteristics, including the birth date, gender, birth weight and gestational age (GA), were collected. The GA was calculated by the delivery date minus the last menstrual period (LMP). Newborns with missing information and non-singletons were removed. According to clinical definition, less than 37 completed gestational weeks is considered a preterm birth. Moreover, we also excluded samples with GA less than 32 weeks or greater than 44 weeks and birth weight less than $1.0 \mathrm{~kg}$ or more than $5.5 \mathrm{~kg}$. Finally, we selected 429,865 singleton newborns for analysis.

\section{Air pollution data}

We employed the Weather Research and Forecasting Model Coupled with Chemistry (WRF/Chem, version 3.5) [51] to simulate the daily $\mathrm{PM}_{2.5}$ concentration in Hubei Province and its surrounding areas. The initial meteorological data in 2014 were extracted from the National Centres for Environmental Prediction Final Operational Global Analysis data (http://rda.ucar.edu/datasets/ds083
.2/). Simulated meteorological data generated by WRF modelling were validated by meteorological data from China Earth International Exchange stations. The modelled $\mathrm{PM}_{2.5}$ concentrations were then downscaled to a resolution of $1 \mathrm{~km} \times 1 \mathrm{~km}$ using a Gaussian downscaling method based on a $\mathrm{PM}_{2.5}$ emissions inventory and wind data (http://inventory.pku.edu.cn/) and validated by air quality monitoring (AQM) data (http://beijingair.sinaa pp.com/). For further details on the model evaluation, please see Shen et al. [52].

The daily $\mathrm{PM}_{2.5}$ concentrations in 2014 at the sub-district level were calculated by overlaying the sub-district administrative shapefile of Hubei and $1 \mathrm{~km} \times 1 \mathrm{~km}$ grid data using ArcGIS 10.3. The formula is shown in Eq. (1):

$$
C_{k}=\sum_{i=1}^{m} \frac{S_{i k}}{S_{k}} C_{i}
$$

where $C_{k}$ and $C_{i}$ represent the daily average $\mathrm{PM}_{2.5}$ concentrations in sub-district $k$ and grid $i$, respectively; $m$ is the total number of grids with intersections with sub-district $k$; $S_{i k}$ is the area of the corresponding intersection; and $S_{k}$ is the total area of sub-district $k$.

Given that AQM data before 2014 are not available in Hubei Province, we only simulated the daily $\mathrm{PM}_{2.5}$ concentrations in 2014 and replaced 2013 concentrations using the same period for each sub-district. Given that a pregnancy term covers approximately $75 \%$ of a year and 
considering the seasonality of air pollutants [53], calculating the pollution exposure during the entire pregnancy is superior to using an annual average concentration [2, 33]. After the daily concentrations were averaged, the spatial distribution of the annual $\mathrm{PM}_{2.5}$ concentrations in 2014 at the sub-district level in Hubei Province was determined, as shown in Fig. 2.

\section{Area-level income data}

Family income was not available in the birth records, and thus we instead collected annual income at the district/county level from the Hubei Statistical Yearbook 2014 [54]. The income data of each district/county in the yearbook consisted of two columns, urban per capita disposable income (UDI) and rural per capita net income (RNI), which represent the income status of urban and rural residents in this district/county, respectively. We assigned UDI to pregnant women living in a city proper or county town and RNI to three other urban-rural types (See "Methods").

\section{Methods}

Regional division and definition of urban-rural continuum Figure 3 provides an overview of the methods used in this study. First, we divided Hubei Province into three regions for comparative analysis. The east includes Wuhan (WH), Xianning (XN), Huangshi (HS), Huanggang (HG), Ezhou (EZ), Xiantao (XT), Xiaogan (XG), Tianmen (TM) and Qianjiang (QJ). The middle includes Jingzhou (JZ), Jingmen (JM), Xiangyang (XY) and Suizhou (SZ). The west includes Enshi (ES), Yichang (YC), Shiyan (SY) and Shennongjia (SNJ). Heterogeneity of physical and socioeconomic conditions was noted among these three regions. The east is the focus of economic development in the province and is also called Wuhan Metropolitan Area, while the terrain in the west is mainly mountainous with a sparse population and under-developed economy (Fig. 1).

We also defined five types of urban-rural continua according to the Urban-Rural Classification and Codes (URCC) by the China National Bureau of Statistics using the indicators of population and economic development [55]. The URCC includes three main urban-rural categories: district (code: 110), township (120) and countryside (200). Sub-district is the smallest administration cell and census tract in China and include several types, such as jiedao, zhen, and xiang. All sub-districts in the districts are called jiedao (city proper, i.e., the most urbanized areas of central cities) or zhen (suburb, i.e., areas adjacent to city proper). Township refers to the zhen in the counties and can be further divided into two types: county town (121) and general town (122). The county town is the seat of the county government, and the urbanized areas in this location are inferior to the city proper but superior to the suburbs. In addition, counties also include other

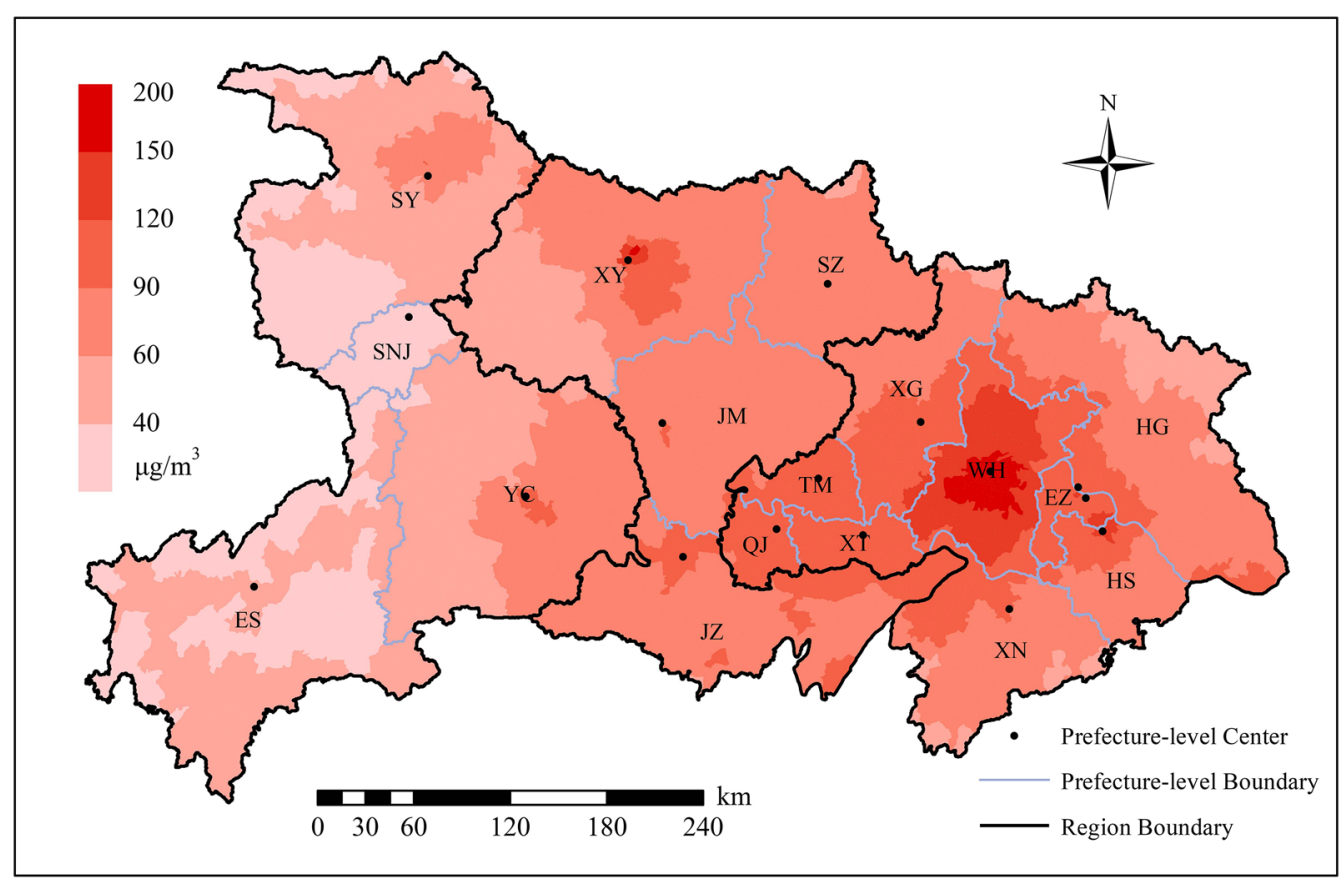

Fig. 2 Spatial distribution of annual $\mathrm{PM}_{2.5}$ concentration at the sub-district level in 2014 in Hubei Province 

1. Sample selection criteria:
(1) Maternal residence information at the sub-district scale is available;
(2) No missing variables for mother and newborn;
(3) Singleton newborns with gestational age between 32 and 44 weeks and birthweight between 1.0 and $5.5 \mathrm{~kg}$.
2. Regional division and definition of urban-rural continuum:
(1) Hubei Province were divided into three regions for comparative analysis. The following spatial analysis and multilevel modelling were conducted by region, respectively;
(2) Five urban-rural types were treated as independent variables in multilevel models.
4. Multilevel logistic models:
(1) Model 1: urban-rural types;
(2) Model 2: $\mathrm{PM}_{2.5}$ exposure;
(3) Model 3: urban-rural types + covariates;
(4) Model 4: $\mathrm{PM}_{2.5}$ exposure + covariates;
(5) Model 5: urban-rural types $+\mathrm{PM}_{2.5}$ exposure + covariates.
(1) Variables used: annual average $\mathrm{PM}_{2.5}$ concentration and average preterm rate at the sub-district level;
(2) Spatial correlation index: bivariate Moran's I and LISA; between two variables according to bivariate LISA.
3. Spatial correlation analysis
(3) Geo-visualizing the relationship

Fig. 3 Overview of the methodology in this study

Table 1 The definition of urban-rural continuum

\begin{tabular}{lllll}
\hline Code & Category & jiedao & zhen & xiang \\
\hline 110 & District & City proper & Suburb & \\
120 & Township & & & \\
121 & County town & & County town & \\
122 & General town & & General town & \\
200 & Countryside & & & Countryside \\
\hline
\end{tabular}

areas called xiang, which is the countryside. Thus, we finally divided all sub-districts into five types of urbanrural continua: city proper, county town, suburb, general town and countryside (Table 1), and this order reflects a decrease in urbanization and SES. Briefly, city proper and county town represent core urban areas with different scales, while suburbs, general town and countryside are different types of rural areas. Compared with suburbs, general town and countryside are more remote from urban areas, and the latter is a more deprived area than the former.

\section{Spatial correlation analysis}

Before regression modelling, we used a series of spatial correlation methods to measure and geo-visualize the spatial dependence between air pollution and the risk of PTB. The global spatial autocorrelation index is similar to Pearson's correlation coefficient. However, the spatial adjacency is considered, and its general formula is measured by the Moran index (Moran's I) in Eq. (2) [56, 57]:

$$
\text { Moran' } S I=\frac{\sum_{i=1}^{n} \sum_{j=1}^{n} w_{i j}\left(x_{i}-\bar{x}\right)\left(x_{j}-\bar{x}\right)}{S^{2}(x) \sum_{i=1}^{n} \sum_{j=1}^{n} w_{i j}}
$$

where $x_{i}$ represents the attribute value of spatial unit $i ; \bar{x}$ and $S^{2}$ are the corresponding average and variance value of the entire region, respectively; $w_{i j}$ is the element of the spatial weight matrix based on the first-order Rook contiguity method; and $n$ is the total number of spatial units in the region.

The above index is applicable to single attribute. Bivariate Moran's I (BiMoran's I) measures the spatial correlation of two attributes by replacing $x_{j}$ with $y_{j}$, and the bivariate local indicator of spatial association (BiLISA) is used to measure this correlation between a spatial unit $i$ 
and its neighbourhoods as noted in the following Eqs. (3) [58] and (4) [59]:

$$
\begin{aligned}
& \text { BiMoran' }^{\prime} I=\frac{\sum_{i=1}^{n} \sum_{j=1}^{n} w_{i j}\left(x_{i}-\bar{x}\right)\left(y_{j}-\bar{y}\right)}{S(x) S(y) \sum_{i=1}^{n} \sum_{j=1}^{n} w_{i j}} \\
& \operatorname{BiLISA}_{i}=z_{x i} \sum_{j=1}^{n} w_{i j} z_{y j}
\end{aligned}
$$

where $z_{x i}$ and $z_{y i}$ represent standardized values (scaled by standard deviation) of attribute variables $x$ and $y$ of each spatial unit $i ; S(x)$ and $S(y)$ are their standard deviation; and the other symbols are the same as noted in Eq. (2).

Here, spatial units refer to each sub-district, and we used annual $\mathrm{PM}_{2.5}$ concentration as the explanatory variable $x$. Given the limited number of samples in many sub-districts, i.e., the small population problem [60], we constructed a smoothing window [61] to calculate the spatial average PTB rate as the dependent variable $y$ for each sub-district. Specifically, we replaced sub-district polygons with their geometric centroids and took $50 \mathrm{~km}$ as the spatial window radius to calculate the average rate for each centroid. Figure 4 shows the spatial distribution pattern of the PTB rate in Hubei Province.

According to the $z_{x}$, BiLISA value and its significance, the sub-districts can be divided into five categories: when $B i L i S A>0$ and $p \leq 0.05$, a significantly positive spatial correlation is noted between air pollution and preterm rate, including types of $\mathrm{H}-\mathrm{H}$ (when $z_{x}>0$, i.e., high pollution with high preterm rate) and $\mathrm{L}-\mathrm{L}$ (when $z_{x}<0$, i.e., low pollution with low preterm rate); when BiLiSA $<0$ and $p \leq 0.05$, a significantly negative correlation is noted, including types of $\mathrm{H}-\mathrm{L}$ (when $z_{x}>0$, i.e., high pollution with low preterm rate) and $\mathrm{L}-\mathrm{H}$ (when $z_{x}<0$, i.e., low pollution with high preterm rate); finally, when $p>0.05$, there is no significant correlation [62]. We used Geoda [63] to calculate the above indexes for the whole province and three regions.

\section{Multilevel logistic model}

Then, we used multilevel logistic models to analyse whether and to what extent air pollution exposure increased the risk of PTB during the entire pregnancy. Compared with a fixed logistic model, a multilevel model has a random effect to stratify samples to describe the potential group differences and unobserved variables. The general form of the model is as follows:

$$
\ln \left[\frac{P\left(y_{i j}=1\right)}{1-P\left(y_{i j}=1\right)}\right]=\beta_{0}+\sum_{m=1}^{p} \beta_{m} x_{i j m}+\sum_{n=1}^{q} \beta_{n} x_{j n}+u_{j}+\varepsilon_{i j}
$$

where $P$ is the probability of the event (for a premature infant, $y=1$ ); $p$ and $q$ are the total number of variables in the level 1 and 2 , respectively; and $u_{j}$ is the random effect.

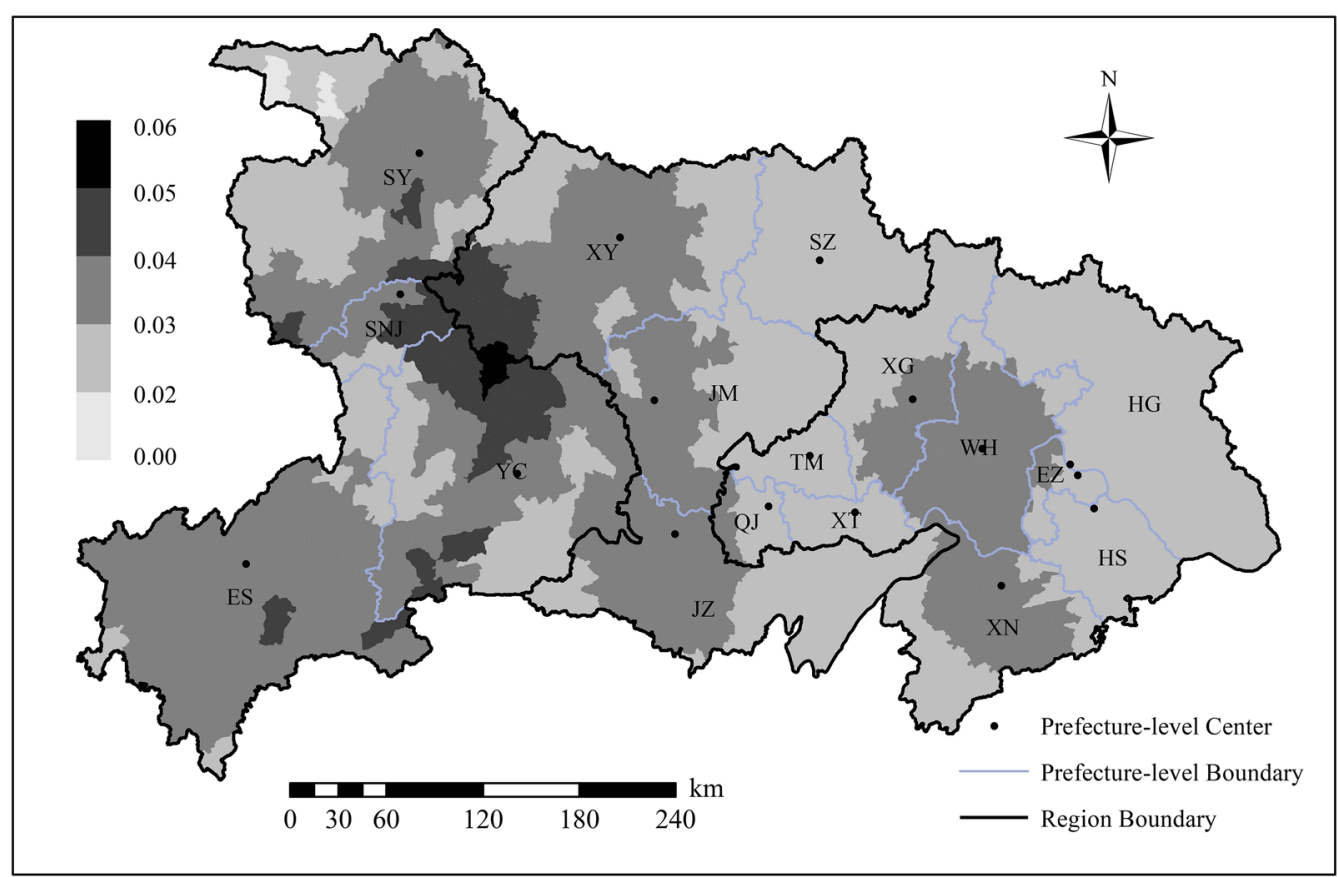

Fig. 4 Distribution of preterm birth rate at sub-district level based on the spatial smoothing method in Hubei Province 
In this study, the random effect was based on the sub-district identifier. Explanatory variables included maternal residence types in the urban-rural continua, $\mathrm{PM}_{2.5}$ exposure and other individual-level and area-level covariates. $\mathrm{PM}_{2.5}$ exposure was measured as the average daily concentration of maternal permanent residence at the sub-district level during the whole pregnancy for each sample, which can prevent discussion of seasonal and long-term trends as we only used one year's neonatal samples. The effects were reported by a $30-\mu \mathrm{g} /$ $\mathrm{m}^{3}$ increase. Individual-level covariates contained categorical variables of maternal nationality (Han or minority), age $(<20,20-24,25-29,30-34$, or $\geq 35$ years $)$, educational level (primary, secondary, or tertiary), regular health or physical checks (less than 5 times or not), month of conception (January as reference), new-born sex (male or female), and parity (firstborn or non-firstborn). The area-level covariate referred to annual income at the district/county level and was scaled by provincial standard deviation. To test the possible non-monotonic relationship, we also added the squared term of income into models.

In the framework of multilevel models, we constructed a series of models. Model 1 contains only residence type variables to test the overall difference of PTB risk, while model 2 includes only the $\mathrm{PM}_{2.5}$ exposure variable. As controlled factors, individual- and area-level variables were added in models 3 and 4, respectively. Model 5 is the final model and included all variables mentioned above. Furthermore, to investigate whether the effects are varied, we also assessed all models using samples for each region. All of the multilevel models were tested using the lem4 package of the $\mathrm{R}$ software environment [64].

\section{Results}

\section{Descriptive characteristics}

Table 2 lists the samples of newborns used in this study and basic indicators of population and economy in 2014 for the entire province and each prefecture-level city. The capita GDP (GDP/Pop in Table 2) varies greatly in different cities. The values for WH, HS, EZ and QJ in the east, $\mathrm{XY}$ in the middle and $\mathrm{YC}$ in the west are greater than the provincial average, while the capita GDP in ES in the west is the lowest. The ratio of samples to total population is $7.39 \%$ for the whole province, which is close to the birth rate of Hubei Province in 2014 (11.86\%o). Overall, our sample data are representative of newborns in the study area.

Table 3 shows the descriptive characteristic of the sample data for the entire province and three regions. The east accounts for greater than half of the newborns, as it is a densely populated area in the province. In contrast, the west has the least newborns. The overall prevalence of PTB is $2.98 \%$ in Hubei, and minimal differences are noted among three regions. The majority of pregnant mothers are located in the city proper or general town, but there are distinct differences in the proportion in various urban-rural

Table 2 Overview of neonatal samples and indicators of population and economy in 2014

\begin{tabular}{|c|c|c|c|c|c|c|}
\hline Province/city & Hubei & WH & $\mathbf{X N}$ & HS & HG & $\mathrm{EZ}$ \\
\hline Pop $(10,000)$ & 5815.99 & 1033.80 & 248.92 & 244.92 & 626.25 & 105.88 \\
\hline GDP (10 billion CNY) & 288.73 & 100.69 & 9.64 & 12.19 & 14.77 & 6.87 \\
\hline GDP/Pop (1,000 CNY) & 49.64 & 97.40 & 38.73 & 49.77 & 23.58 & 64.88 \\
\hline Sample & 429,865 & 68,026 & 33,036 & 26,396 & 52,034 & 10,289 \\
\hline Sample/Pop (\%o) & 7.39 & 6.58 & 13.27 & 10.78 & 8.31 & 9.72 \\
\hline Province/city & XT & $X G$ & TM & QJ & $J Z$ & JM \\
\hline Pop $(10,000)$ & 116.60 & 486.13 & 129.16 & 95.44 & 574.42 & 288.91 \\
\hline GDP (10 billion CNY) & 5.52 & 13.55 & 4.02 & 5.40 & 14.80 & 13.11 \\
\hline GDP/Pop $(1,000$ CNY $)$ & 47.34 & 27.87 & 31.12 & 56.58 & 25.77 & 45.38 \\
\hline Sample & 13,180 & 5,831 & 12,205 & 7,606 & 47,112 & 19,499 \\
\hline Sample/Pop (\%o) & 11.30 & 1.20 & 9.45 & 7.97 & 8.20 & 6.75 \\
\hline Province/city & $X Y$ & SZ & ES & YC & SY & SNJ \\
\hline Pop $(10,000)$ & 560.02 & 218.38 & 331.77 & 410.45 & 337.27 & 7.67 \\
\hline GDP (10 billion CNY) & 31.29 & 7.23 & 6.12 & 31.32 & 12.01 & 0.20 \\
\hline GDP/Pop $(1,000$ CNY) & 55.87 & 33.11 & 18.45 & 76.31 & 35.61 & 26.08 \\
\hline Sample & 49,306 & 22,393 & 32,412 & 6,047 & 24,425 & 68 \\
\hline Sample/Pop (\%o) & 8.80 & 10.25 & 9.77 & 1.47 & 7.24 & 0.89 \\
\hline
\end{tabular}

Pop, total resident population; GDP, gross domestic product; CNY, Chinese yuan 
Table 3 Descriptive characteristics for variables used in multilevel models (\%)

\begin{tabular}{|c|c|c|c|c|}
\hline Variable & Hubei & East & Middle & West \\
\hline Total & 429,865 & 228,603 & 138,310 & 62,952 \\
\hline \multicolumn{5}{|l|}{ GA (weeks) } \\
\hline Mean (Std) & $39.24(1.27)$ & $39.32(1.26)$ & $39.14(1.25)$ & $39.17(1.32)$ \\
\hline$<37$ & 2.98 & 2.91 & 2.94 & 3.32 \\
\hline \multicolumn{5}{|l|}{ Residence types } \\
\hline City proper ${ }^{a}$ & 31.98 & 40.04 & 23.04 & 22.36 \\
\hline County town & 10.45 & 9.94 & 9.10 & 15.24 \\
\hline Suburb & 9.10 & 13.68 & 4.90 & 1.70 \\
\hline General town & 41.19 & 31.81 & 58.65 & 36.89 \\
\hline Countryside & 7.28 & 4.53 & 4.31 & 23.81 \\
\hline \multicolumn{5}{|c|}{$\mathrm{PM}_{2.5}$ exposure $\left(30 \mu \mathrm{g} / \mathrm{m}^{3}\right)$} \\
\hline Mean (Std) & $3.10(1.18)$ & $3.63(1.21)$ & $2.87(0.61)$ & $1.69(0.53)$ \\
\hline \multicolumn{5}{|l|}{ Nationality } \\
\hline Han (Main) ${ }^{a}$ & 96.89 & 99.63 & 99.35 & 81.55 \\
\hline Minority & 3.11 & 0.37 & 0.65 & 18.45 \\
\hline \multicolumn{5}{|l|}{ Age (years) } \\
\hline Mean (Std) & $26.83(4.50)$ & $26.95(4.49)$ & $26.60(4.32)$ & $26.91(4.93)$ \\
\hline$<20$ & 2.29 & 1.95 & 2.08 & 3.96 \\
\hline $20-24$ & 30.49 & 29.85 & 32.04 & 29.39 \\
\hline $25-29^{a}$ & 43.98 & 44.22 & 44.72 & 41.50 \\
\hline $30-34$ & 16.49 & 17.13 & 15.38 & 16.65 \\
\hline$\geq 35$ & 6.75 & 6.85 & 5.79 & 8.49 \\
\hline \multicolumn{5}{|l|}{ Educational level } \\
\hline Elementary & 19.30 & 21.21 & 15.44 & 20.85 \\
\hline Secondary ${ }^{a}$ & 74.79 & 70.70 & 81.20 & 75.55 \\
\hline Tertiary & 5.91 & 8.09 & 3.36 & 3.59 \\
\hline \multicolumn{5}{|c|}{ Frequency of health checks } \\
\hline$<5^{\mathrm{a}}$ & 78.31 & 63.25 & 95.19 & 95.91 \\
\hline$\geq 5$ & 21.69 & 36.75 & 4.81 & 4.09 \\
\hline \multicolumn{5}{|l|}{ Parity } \\
\hline Firstborn & 75.41 & 73.38 & 81.01 & 70.45 \\
\hline Non-Firstborn ${ }^{a}$ & 24.59 & 26.62 & 18.99 & 29.55 \\
\hline \multicolumn{5}{|l|}{ Infant sex } \\
\hline Male ${ }^{a}$ & 54.07 & 54.72 & 53.82 & 52.28 \\
\hline Female & 45.93 & 45.28 & 46.18 & 47.72 \\
\hline \multicolumn{5}{|c|}{ Income $(1,000$ CNY) } \\
\hline Mean (Std) & $14.32(7.20)$ & $15.89(8.15)$ & $13.69(4.82)$ & $9.98(5.75)$ \\
\hline
\end{tabular}

Std, standard deviation; CNY, Chinese yuan

"al indicates reference group

residence types among the three regions. For instance, the proportion of pregnant women is relatively high in the countryside in the west. Moreover, the $\mathrm{PM}_{2.5}$ pollution exposure in the three regions is quite different (Fig. 2). The $q$-statistic in Geodetector (www.geode tector.cn) $[65,66]$ is 0.38 , and the annual $\mathrm{PM}_{2.5}$ concentration is significantly different across the regions at the $p=0.05$ level. Figure 5 shows the average annual

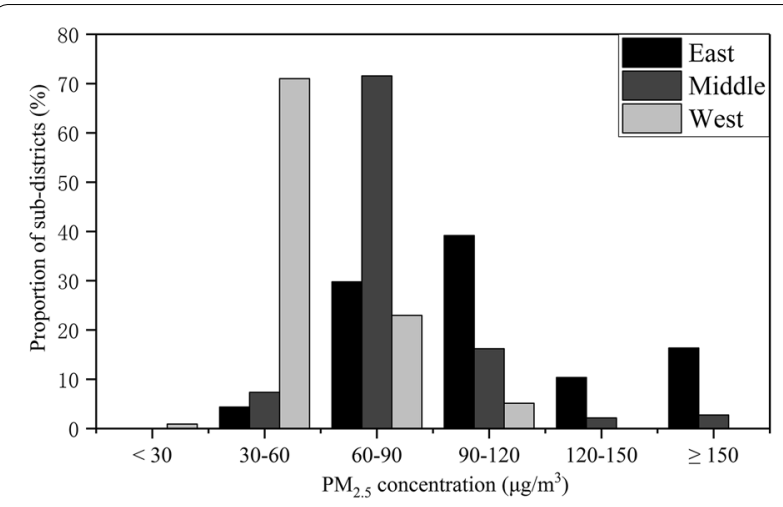

Fig. 5 Annual average $\mathrm{PM}_{2.5}$ concentration histograms for regions

$\mathrm{PM}_{2.5}$ concentration histograms for the regions, which indicates that the east has wide-ranged and serious air pollution, whereas the middle and west mainly has concentrations of $60-90 \mu \mathrm{g} / \mathrm{m}^{3}$ and $30-60 \mu \mathrm{g} / \mathrm{m}^{3}$, respectively.

There is no significant difference in individual-level variables among regions except for nationality and the frequency of physical checks. The west has a greater proportion of minority nationalities than the others, as it includes all ethnic minority autonomous areas in Hubei. Moreover, in the middle and west, the majority of pregnant women have less than five health checks during pregnancy, which might be attributed to the fact that these regions have an under-developed economy and fewer medical facilities. In addition, most people live in general towns and countryside in these regions. Arealevel income gaps exist in three regions. The average income in the east is the highest, while that in the west is the lowest.

\section{Spatial correlation analyses}

Table 4 presents the results of the global univariate and bivariate Moran's $I$ in the entire province and three regions. The $\mathrm{PM}_{2.5}$ concentration and preterm rate exhibit positive and significant spatial autocorrelation in all cases. The BiMoran's I was close to null in the middle,

Table 4 Calculation of results of global Moran's I ( $p$ values)

\begin{tabular}{lllr}
\hline Variable & PM $_{\mathbf{2 . 5}}$ concentration & Preterm rate & \multicolumn{1}{l}{ Bivariate } \\
\hline Hubei & $0.970(0.00)^{*}$ & $0.861(0.00)^{*}$ & $0.106(0.00)^{*}$ \\
East & $0.968(0.00)^{*}$ & $0.940(0.00)^{*}$ & $0.697(0.00)^{*}$ \\
Middle & $0.872(0.00)^{*}$ & $0.856(0.00)^{*}$ & $-0.004(0.44)$ \\
West & $0.927(0.00)^{*}$ & $0.731(0.00)^{*}$ & $0.049(0.02)^{*}$ \\
\hline
\end{tabular}

Significant level: ${ }^{\prime *} p \leq 0.05$ 
and a weak positive trend was noted over the entire province and in the west. A strong positive correlation was noted in the east.
Figure 6 displays the cluster distribution according to the BiLISA value and its significance for the entire province and three regions. "Red" indicates a positive

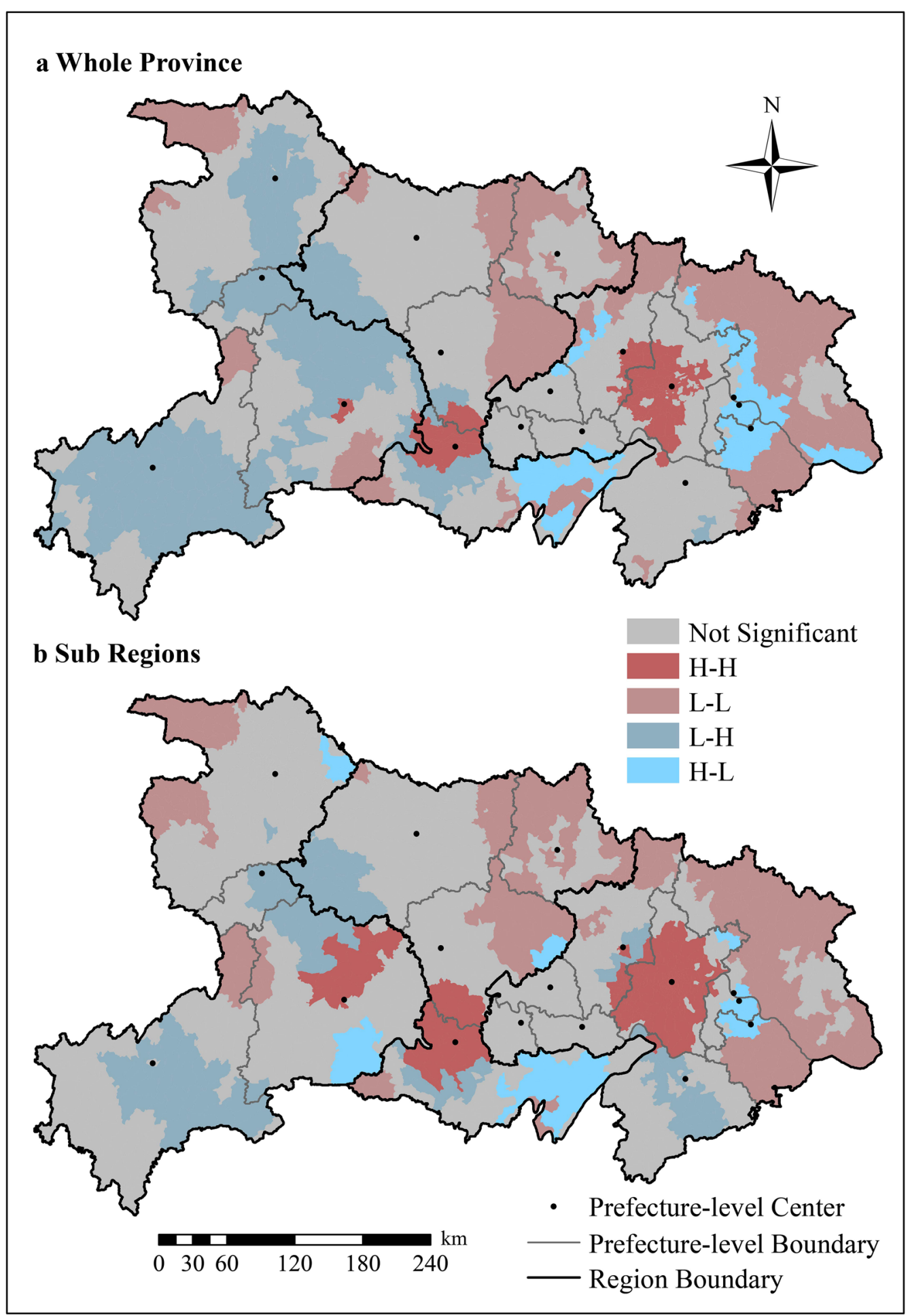

Fig. 6 Spatial distribution of bivariate LISA clusters 
correlation $(\mathrm{H}-\mathrm{H}, \mathrm{L}-\mathrm{L})$ while "blue" indicates a negative correlation $(\mathrm{H}-\mathrm{L}, \mathrm{L}-\mathrm{H})$. From the perspective of the whole province, the $\mathrm{H}-\mathrm{H}$ areas were concentrated in the east and in $\mathrm{JZ}$ in the middle, while $\mathrm{L}-\mathrm{H}$ areas were mostly located in the west. However, the number of $\mathrm{H}-\mathrm{L}$ areas was small, and these areas were scattered in the east and middle. However, L-L areas were widely distributed across Hubei. In terms of the regions, four types of areas appeared in each region. $\mathrm{H}-\mathrm{H}$ and $\mathrm{L}-\mathrm{L}$ areas dominated the east, while the west had larger $\mathrm{L}-\mathrm{H}$ areas.

\section{Multilevel modelling analyses}

Table 5 summarizes the results of all of the models related to $\mathrm{PM}_{2.5}$ exposure variable. The odds ratio (OR) was calculated as $\exp (\beta)$, and the $95 \%$ confidence interval (CI) was reported simultaneously. In the unadjusted full-sample models (model 2), the OR was significantly greater than one (1.06; 95\% CI 1.04-1.09) but no longer statistically significant after adjustment by covariates and urban-rural type variables $(0.98 ; 0.95-1.02$ in model $4,0.99$; $0.95-1.03$ in model 5 ). The models in the middle exhibited similar trends. All ORs were significant in the eastern-sample models regardless of adjustment. In contrast, the results of all the models in the west were insignificant.

Table 6 summarizes the results of all multilevel models involving urban-rural type variables. Model 1 was used to test the difference in PTB risk among various residence types. All ORs were less than one, and most were significant. These results indicate that compared with the city proper, other urban-rural types have a lower risk of PTB. However, the effect did not monotonically decrease as urbanity weakened. Figure 7 presents the trends of the PTB risk magnitudes ordered by urbanity from the strongest to the weakest, and W-shapes are noted across the urban-rural continua for the entire province and all regions. After controlling for covariates in model 3 and considering the $\mathrm{PM}_{2.5}$ exposure in model 5 , the ORs changed slightly compared with model 1 . The entire right side of the confidence intervals of ORs approaches or exceeds one, especially in the east and west, which indicates that the differences in PTB risks among urban-rural types have become less obvious.

Table 5 ORs of $\mathrm{PM}_{2.5}$ exposure variable in multilevel models

\begin{tabular}{|c|c|c|c|c|c|}
\hline \multirow[t]{2}{*}{ Region } & & \multicolumn{4}{|l|}{ OR $(95 \% \mathrm{Cl})$} \\
\hline & & Hubei & East & Middle & West \\
\hline \multirow[t]{3}{*}{ Model } & 2 & $1.06(1.04-1.09)^{*}$ & $1.13(1.10-1.16)^{*}$ & $1.15(1.07-1.23)^{*}$ & $0.93(0.82-1.07)$ \\
\hline & 4 & $0.98(0.95-1.02)$ & $1.12(1.06-1.20)^{*}$ & $1.04(0.96-1.13)$ & $0.88(0.75-1.04)$ \\
\hline & 5 & $0.99(0.95-1.03)$ & $1.12(1.05-1.20)^{*}$ & $1.02(0.94-1.11)$ & $0.83(0.68-1.00)$ \\
\hline
\end{tabular}

$\mathrm{OR}$, odds ratio; $\mathrm{Cl}$, confidence interval

Significant level: ${ }^{\prime *} \mathrm{p} \leq 0.05$

Table 6 ORs of residence type variables in multilevel models

\begin{tabular}{|c|c|c|c|c|c|}
\hline \multirow[t]{2}{*}{ Model } & \multirow[t]{2}{*}{ Type } & \multicolumn{4}{|l|}{ OR (95\% Cl) } \\
\hline & & Hubei & East & Middle & West \\
\hline \multirow[t]{4}{*}{1} & County town & $0.79(0.70-0.89)^{*}$ & $0.74(0.63-0.87)^{*}$ & $0.76(0.60-0.95)^{*}$ & $0.88(0.66-1.16)$ \\
\hline & Suburb & $0.80(0.73-0.89)^{*}$ & $0.79(0.71-0.88)^{*}$ & $0.86(0.68-1.08)$ & $0.97(0.58-1.62)$ \\
\hline & General town & $0.73(0.68-0.78)^{*}$ & $0.72(0.66-0.78)^{*}$ & $0.69(0.61-0.78)^{*}$ & $0.81(0.66-0.99)^{*}$ \\
\hline & Countryside & $0.87(0.79-0.96)^{*}$ & $0.79(0.68-0.92)^{*}$ & $0.75(0.59-0.94)^{*}$ & $0.96(0.78-1.18)$ \\
\hline \multirow[t]{4}{*}{3} & County town & $0.82(0.72-0.93)^{*}$ & $0.76(0.64-0.91)^{*}$ & $0.99(0.77-1.27)$ & $0.74(0.52-1.07)$ \\
\hline & Suburb & $0.85(0.76-0.96)^{*}$ & $0.88(0.75-1.03)$ & $0.80(0.64-1.01)$ & $0.99(0.47-2.10)$ \\
\hline & General town & $0.78(0.69-0.87)^{*}$ & $0.82(0.68-0.99)^{*}$ & $0.74(0.59-0.94)^{*}$ & $0.80(0.45-1.44)$ \\
\hline & Countryside & $0.91(0.78-1.05)$ & $0.91(0.73-1.13)$ & $0.77(0.56-1.06)$ & 0.97 (0.53-1.78) \\
\hline \multirow[t]{4}{*}{5} & County town & $0.81(0.71-0.92)^{*}$ & $0.82(0.68-0.99)^{*}$ & $1.01(0.78-1.30)$ & $0.69(0.47-1.00)$ \\
\hline & Suburb & $0.86(0.76-0.96)^{*}$ & $0.84(0.71-0.98)^{*}$ & $0.82(0.64-1.04)$ & $1.15(0.53-2.48)$ \\
\hline & General town & $0.78(0.69-0.88)^{*}$ & $0.79(0.65-0.96)^{*}$ & $0.75(0.59-0.94)^{*}$ & $0.96(0.52-1.79)$ \\
\hline & Countryside & $0.91(0.78-1.06)$ & $0.87(0.70-1.09)$ & $0.77(0.56-1.06)$ & $1.14(0.61-2.13)$ \\
\hline
\end{tabular}

$\mathrm{OR}$, odds ratio; $\mathrm{Cl}$, confidence interval

Significant level: "*" $p \leq 0.05$ 


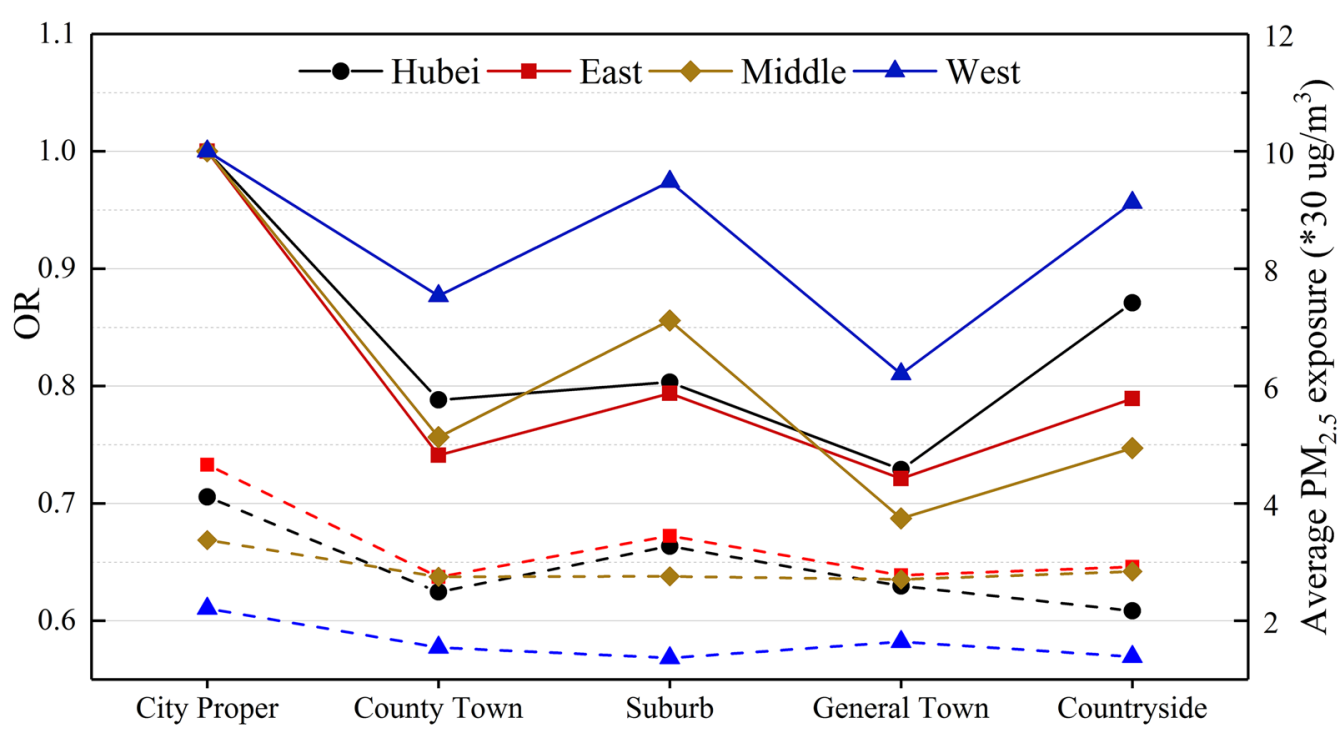

Fig. 7 The odds ratios of PTB (solid line) and average $\mathrm{PM}_{2.5}$ exposure (dashed line) of five urban-rural types

Table 7 shows the ORs of covariates used in the final model (model 5). No significant difference was observed in the risk of PTB between the Han (China's main nationality) and minority nationalities in Hubei and any region. Pregnant women less than 20 years old have a higher risk of PTB, and the risk continues to increase when pregnant women are over 30 years old. Those with higher education have a significantly higher risk in the west, but no significant differences were found in other cases. Regular health checks can significantly reduce the risk of PTB in the entire province and the east. Firstborn infants in the middle have a higher risk of PTB, but this correlation was not significant in other regions. Female babies have a lower risk than males for the entire province and all regions. No significant non-monotonicity was found for the effect of income on the risk of PTB in any single region, but the direction of the effect varied by region. Specifically, the income could statistically increase the risk of PTB in the full-sample model as well as in the middle. The

Table 7 ORs of individual socio-demographic variables in model 5

\begin{tabular}{|c|c|c|c|c|}
\hline \multirow[t]{2}{*}{ Variable } & \multicolumn{4}{|l|}{ OR $(95 \% \mathrm{Cl})$} \\
\hline & Hubei & East & Middle & West \\
\hline Minority (ref: Han) & $1.04(0.93-1.16)$ & $0.99(0.66-1.49)$ & $1.26(0.88-1.80)$ & $0.95(0.84-1.08)$ \\
\hline \multicolumn{5}{|l|}{ Age (ref: 25-29) } \\
\hline$<20$ & $1.32(1.18-1.48)^{*}$ & $1.20(1.01-1.44)^{*}$ & $1.38(1.13-1.69)^{*}$ & $1.51(1.21-1.88)^{*}$ \\
\hline $20-24$ & $0.97(0.93-1.02)$ & $0.93(0.87-0.99)^{*}$ & $0.96(0.89-1.04)$ & $1.18(1.06-1.33)^{*}$ \\
\hline $30-34$ & $1.25(1.19-1.32)^{*}$ & $1.17(1.09-1.26)^{*}$ & $1.38(1.26-1.50)^{*}$ & $1.33(1.17-1.51)^{*}$ \\
\hline$\geq 35$ & $1.86(1.75-1.98)^{*}$ & $1.84(1.69-2.00)^{*}$ & $1.84(1.64-2.07)^{*}$ & $1.94(1.68-2.24)^{*}$ \\
\hline \multicolumn{5}{|l|}{ Education (ref: secondary) } \\
\hline Elementary & $0.97(0.92-1.02)$ & $0.94(0.88-1.01)$ & $0.96(0.87-1.05)$ & $1.08(0.96-1.22)$ \\
\hline Tertiary & $0.98(0.91-1.06)$ & $0.95(0.87-1.05)$ & $0.95(0.80-1.14)$ & $1.26(1.01-1.59)^{*}$ \\
\hline Regular health checks (ref: check < 5) & $0.89(0.83-0.95)^{*}$ & $0.84(0.77-0.91)^{*}$ & $0.91(0.78-1.08)$ & $1.22(0.95-1.56)$ \\
\hline Firstborn (ref: non-firstborn) & $1.04(0.99-1.09)$ & $0.98(0.92-1.04)$ & $1.22(1.12-1.33)^{*}$ & $0.98(0.89-1.09)$ \\
\hline Female (ref: male) & $0.79(0.76-0.82)^{*}$ & $0.78(0.74-0.82)^{*}$ & $0.79(0.75-0.85)^{*}$ & $0.84(0.77-0.92)^{*}$ \\
\hline Income & $1.03(0.96-1.10)$ & $0.96(0.86-1.08)$ & $0.91(0.77-1.07)$ & $0.94(0.57-1.52)$ \\
\hline Income $\wedge 2$ & $1.04(1.01-1.07)^{*}$ & $1.02(0.98-1.06)$ & $1.65(1.34-2.03)^{*}$ & $0.69(0.52-0.93)^{*}$ \\
\hline
\end{tabular}

OR, odds ratio; $\mathrm{Cl}$, confidence interval

Significant level: ${ }^{u * "} p \leq 0.05$ 
opposite effect was noted in the west, and the effect was not significant in the east.

\section{Discussion}

This study aims to explore the relationships between air pollution and the risks of PTB as well as the risk disparities across different regions and urban-rural continua. We found that the results tend to support the argument that higher pollution exposure during pregnancy can increase the risks of PTB, but some variations were noted in three regions. Spatial analysis showed that the spatial correlation was significantly positive between air pollution and preterm rate in the east and west with an insignificant correlation in the middle. Multilevel models further demonstrated that the risk of PTB increased by $12 \%(95 \%$ CI $7 \%-18 \%)$ for a $30-\mu \mathrm{g} / \mathrm{m}^{3}$ increase in average $\mathrm{PM}_{2.5}$ exposure during pregnancy after controlling for covariates and urban-rural variables in the east, while no significant correlation was found in other cases.

Serious air pollution has become a global problem, especially in many developing countries, such as China, India, and countries in western and northern Africa [67]. These conditions significantly threaten human health and living quality, and attention should be given to these issues. Although many studies have investigated the relationships between air pollution and pregnancy outcomes in both developed and developing countries, such as the US [22, 25, 68], Europe [24, 69], China [21, 70, 71] and other countries [72, 73], their findings are inconclusive. Parker et al. hypothesized that these different results may be due to the composition of PM differences and exposure measurement errors [31]. Fleischer et al. suggested that the differences might be related to the threshold effect and the stage of economic development [30]. However, little research has examined the effect of the economy-environment context of location from the perspective of regional and urban-rural disparities in pollution-health relationships.

In fact, another problem is the imbalance in regional and urban-rural development accompanied by the inequality in socioeconomic conditions and differences in environment quality. In the east area in this study, which exhibits the most developed economy and the most serious levels of pollution, the pollution-PTB relationship was significantly positive, but area-level income was not associated with PTB. Conversely, in the west, where the air pollution and economic level were the lowest in the province, increased area-level income could significantly reduce the risk of PTB, while the pollution-PTB relationship was insignificant. Interestingly, the direction of the income effect was positive for PTB in the middle, indicating that economic growth will occur at the expense of health in some cases. We could infer that pollution exposure has a threshold and nonlinear effect $[5,30,74]$, and the ranks of importance of income and pollution to health will vary based on geographical context.

Furthermore, the U-shaped pattern of the relationship between economy and environmental quality may explain why the risk of PTB observed in our study does not change monotonically across the urban-rural continuum. We also found that the crude disparity in the risks of PTB followed the same W-shaped pattern across the urban-rural continuum for the entire province and for all regions. In other words, the risks of PTB present a V- or U-shaped structure in urban settings and rural settings. This finding could indicate that an urban disadvantage and rural disadvantage exist simultaneously, and the lowest risk of PTB occurs at a moderate level for both urbanity and rurality. Part of the disparity could be statistically explained by air pollution exposure. In the multilevel models, most of the ORs of other urban-rural types were increased compared with the city proper (though still less than one) when the $\mathrm{PM}_{2.5}$ exposure was controlled for. These findings potentially suggest that the air pollution pressure is likely an important aspect of the urban disadvantage. Thus, a finer classification of urban-rural areas is necessary. This information could potentially improve our understanding of the pollution-health relationships and be helpful for governments to develop environmental and public health policy better targeted at appropriate places.

It should be noted that the W-shaped pattern may not always be fixed for other countries and regions, and the shape also depends on the contexts among various urban-rural areas. In China, although some cities have been highly developed (for example, Wuhan is the largest city in central China and one of the mega cities in the whole nation) [75], many rural areas in suburbs and counties are still regarded as poverty-stricken regions with poor living conditions, low-level medical facilities and inconvenient transportation. The economy is driven by energy in most places in China, and thus the economy-environment relationship is mainly located in the left half of the Environmental Kuznets Curve. Similar circumstances likely exist in rapidly developing countries. However, the economy-environment contexts may differ in some developed countries that have experienced suburbanization; thus, some suburbs have more advantages than the city proper in terms of both living conditions and environment quality. Therefore, the urban-rural division should take into account the actual condition of study area. For example, the urban hierarchy and distance to the urban core can be used as important references. In developed countries, several indicators, such as the social deprivation index, may be helpful to finely 
distinguish different types of suburbs and then further categorize these suburbs into urban-rural types.

Regarding other covariates, this study shows a U-shaped relationship between maternal age and risk of PTB, and firstborn and male babies have a higher risk of PTB than non-firstborn and female infants. Race and ethnicity were often considered in previous studies, but we did not find a significant difference in the risks of PTB between the minority and main nationalities in all regions. Regular examination during pregnancy can reduce the risk of PTB, which is supported by the eastern region results. However, the proportion of pregnant women with regular physical exams in the middle and western regions is very small, which may be related to the incomplete health check records acquired from the hospitals in these regions.

Some limitations should be noted. First, data on some individual-level information, such as occupation, medical history and lifestyle variables, were not considered in the analysis mainly due to the unavailability of these data in the restricted medical record data. Second, given that the income variable is not available in the dataset, we instead used district/county-level annual income, which failed to distinguish the income effect of the five urban-rural types. Fortunately, urban-rural types were treated as dummy variables in the multilevel models, and these data could partly reflect the SES and income effect. Third, other pollutants, such as $\mathrm{NO}_{2}, \mathrm{SO}_{2}, \mathrm{O}_{3}[5,76]$ and temperature [77-79], which might also be risk factors of PTB, were not controlled in this study. It should be noted that $\mathrm{PM}_{2.5}$ is the main air pollutant in most regions of China, and the spatial variation of temperature in the long term is not notable. As indicated in some prior studies, the adjustment of multi-pollutants and temperature was insignificant $[5,27]$. However, without controlling for these factors, the effect of $\mathrm{PM}_{2.5}$ might be overestimated. Finally, given the uncertainty and unavailability of where women's activities took place in daily life, the air pollution concentration of registered residences may not accurately reflect the real air pollution exposure to pregnant women. Future research could measure the mobility-based air pollution exposure for pregnant women and estimate their health effects.

\section{Conclusions}

This study aimed to examine regional and urban-rural disparities in the relationships between PTB risk and air pollution in Hubei Province, China, and to determine how the risk changes as urbanity decreases and to what extent air pollution exposure during pregnancy can explain the variations. Spatial correlation analysis indicated that air pollution exposure and PTB exhibited a significant and positive correlation in areas with serious air pollution burden. Multilevel logistic regressions showed that the risk of PTB in the entire province and all regions followed the same W-shaped pattern as urbanity decreases and rurality increases. The modelling results also found that air pollution exposure during pregnancy could increase the risk of PTB and that a high level of air pollution exposure may be an important disadvantage for urban pregnant women in this setting.

\section{Abbreviations \\ PM: Particulate matter; SES: Socioeconomic status; PTB: Preterm birth; LBW: Low birth weight; SGA: Small for gestational age; GA: Gestational age; LMP: Last menstrual period; AQM: Air Quality Monitoring; URCC: Urban-Rural Classification Codes by China National Bureau of Statistics; OR: Odds ratio; Cl: Confidence interval.}

\section{Acknowledgements}

We are grateful for the valuable suggestions on the model validation from Professor Guanpeng Dong in Henan University.

\section{Authors' contributions}

$L L$ and $J M$ contributed to the design and analysis of the study and the writing of the manuscript. JM and LL contributed to revising the paper. YC, LF and SW provided the neonatal and maternal clinical dataset, and XY and ST provided the air pollution data. All authors read and approved the final manuscript.

\section{Funding}

This research was supported by National Natural Science Foundation of China (Grant No. 41671497).

\section{Availability of data and materials}

The datasets collected and analysed in this study are not available in original form due to confidentiality requirements, but part of the anonymized data is available from the corresponding author upon request.

\section{Ethics approval and consent to participate}

Not applicable.

\section{Consent for publication}

Not applicable.

\section{Competing interests}

The authors declare that they have no competing interests.

\section{Author details \\ ${ }^{1}$ Beijing Key Laboratory for Remote Sensing of Environment and Digital Cities, Faculty of Geographical Science, Beijing Normal University, Beijing 100875. China. ${ }^{2}$ Tongji Hospital of Tongji Medical College, Huazhong University of Sci- ence and Technology, Wuhan 430030, China. ${ }^{3}$ College of Urban and Environ- mental Sciences, Peking University, Beijing 100871, China.}

Received: 22 January 2020 Accepted: 15 June 2020

Published online: 20 June 2020

\section{References}

1. Samet JM, White RH. Urban air pollution, health, and equity. J Epidemiol Commun H. 2004;58(1):3-5.

2. Heft-Neal S, Burney J, Bendavid E, Burke M. Robust relationship between air quality and infant mortality in Africa. Nature. 2018;559(7713):254-8.

3. Kramer MS. Intrauterine growth and gestational duration determinants. Pediatrics. 1987:80:502-11.

4. Berkowitz GS, Papiernik E. Epidemiology of preterm birth. Epidemiol Rev. 1993:15:414-43.

5. Li SS, Guo YM, Williams G. Acute impact of hourly ambient air pollution on preterm birth. Environ Health Persp. 2016;124(10):1623-9. 
6. Fu JY, Jiang D, Lin G, Liu K, Wang Q. An ecological analysis of PM2.5 concentrations and lung cancer mortality rates in China. BMJ Open. 2015;5(11):e009452

7. Brook RD, Rajagopalan S, Pope CA, Brook JR, Bhatnagar A, Diez-Roux AV, Holguin F, Hong YL, Luepker RV, Mittleman MA, Peters A, Siscovick D, Smith SC, Whitsel L, Kaufman JD. Particulate matter air pollution and cardiovascular disease: an update to the scientific statement from the American Heart Association. Circulation. 2010;121:2331-78.

8. Pope CA, Brook RD, Burnett RT, Dockery DW. How is cardiovascular disease mortality risk affected by duration and intensity of fine particulate matter exposure? An integration of the epidemiologic evidence. Air Qual Atmos HIth. 2011;4(1):5-14

9. Dominici F, Peng RD, Bell ML, Pham L, McDermott A, Zeger SL, Samet JM. Fine particulate air pollution and hospital admission for cardiovascular and respiratory diseases. Jama J Am Med Assoc. 2006;295(10):1127-34.

10. Ge EJ, Lai KF, Xiao X, Luo M, Fang ZF, Zeng YJ, Ju H, Zhong NS. Differential effects of size-specific particulate matter on emergency department visits for respiratory and cardiovascular diseases in Guangzhou, China. Environ Pollut. 2018;243(12):336-45.

11. Chen YY, Ebenstein A, Greenstone M, Li HB. Evidence on the impact of sustained exposure to air pollution on life expectancy from China's Huai River policy. P Natl Acad Sci USA. 2013;110(32):12936-41.

12. Liu Y, Zhao NZ, Vanos JK, Cao GF. Revisiting the estimations of PM2.5attributable mortality with advancements in PM2.5 mapping and mortality statistics. Sci Total Environ. 2019;666:499-507.

13. Yu HJ, Yu M, Gordon SP, Zhang RL. The association between ambient fine particulate air pollution and physical activity: a cohort study of university students living in Beijing. Int J Behav Nutr Phy. 2017;14:136.

14. An RP, Shen J, Ying BB, Tainio M, Andersen ZJ, de Nazelle A. Impact of ambient air pollution on physical activity and sedentary behavior in China: a systematic review. Environ Res. 2019;176:108545.

15. Kim KN, Lim YH, Bae HJ, Kim M, Jung K, Hong YC. Long-term fine particulate matter exposure and major depressive disorder in a communitybased urban cohort. Environ Health Persp. 2016;124(10):1547-53.

16. Power MC, Kioumourtzoglou MA, Hart JE, Okereke OI, Laden F, Weisskopf MG. The relation between past exposure to fine particulate air pollution and prevalent anxiety: observational cohort study. BMJ Brit Med J. 2015;350:h1111

17. Wang RY, Liu Y, Xue DS, Yao Y, Liu PH, Helbich M. Cross-sectional associations between long-term exposure to particulate matter and depression in China: the mediating effects of sunlight, physical activity, and neighborly reciprocity. J Affect Disorders. 2019;249:8-14.

18. Saigal S, Doyle LW. An overview of mortality and sequelae of preterm birth from infancy to adulthood. Lancet. 2008;371(9608):261-9.

19. Whincup PH, Kaye S, Owen CG, Huxley R, Cook DG. Birth weight and risk of type 2 diabetes: a quantitative systematic review of published evidence. J Epidemiol Commun H. 2008;62(Suppl 1):A15-6.

20. Liu L, Johnson HL, Cousens S, Perin J, Scott S, Lawn JE, Rudan I, Campbell H, Cibulskis R, Li MY, Mathers C, Black RE. Global, regional, and national causes of child mortality: an updated systematic analysis for 2010 with time trends since 2000. Lancet. 2012;379:2151-61.

21. Zhao QG, Liang ZJ, Tao SJ, Zhu JA, Du YK. Effects of air pollution on neonatal prematurity in Guangzhou of China: a time-series study. Environ Health Glob. 2011;10:2.

22. Chang HH, Reich BJ, Miranda ML. Time-to-event analysis of fine particle air pollution and preterm birth: results from North Carolina, 2001-2005. Am J Epidemiol. 2012;175(2):91-8.

23. Kloog I, Melly SJ, Ridgway WL, Coull BA, Schwartz J. Using new satellite based exposure methods to study the association between pregnancy pm(2.5) exposure, premature birth and birth weight in Massachusetts. Environ Health-Glob. 2012;11:40.

24. Schifano P, Lallo A, Asta F, De Sario M, Davoli M, Michelozzi P. Effect of ambient temperature and air pollutants on the risk of preterm birth, Rome 2001-2010. Environ Int. 2013;61:77-87.

25. Savitz DA, Bobb JF, Carr JL, Clougherty JE, Dominici F, Elston B, Ito K, Ross Z, Yee M, Matte TD. Ambient fine particulate matter, nitrogen dioxide, and term birth weight in New York, New York. Am J Epidemiol. 2014;179(4):457-66

26. Lee SJ, Hajat S, Steer PJ, Filippi V. A time-series analysis of any short-term effects of meteorological and air pollution factors on preterm births in London, UK. Environ Res. 2008;106(2):185-94.
27. Johnson S, Bobb JF, Ito K, Savitz DA, Elston B, Shmool JLC, Dominici F, Ross Z, Clougherty JE, Matte T. Ambient fine particulate matter, nitrogen dioxide, and preterm birth in New York City. Environ Health Persp. 2016;124(8):1283-90

28. Li $X Y$, Huang $S Q$, Jiao AQ, Yang $X H$, Yun JF, Wang $Y X$, Xue XW, Chu YY, Liu FF, Liu YS, Ren M, Chen X, Li N, Lu YA, Mao ZF, Tian LQ, Xiang H. Association between ambient fine particulate matter and preterm birth or term low birth weight: an updated systematic review and meta-analysis. Environ Pollut. 2017:227:596-605.

29. He JR, Liu Y, Xia XY, Ma WJ, Lin HL, Kan HD, Lu JH, Feng Q, Mo WJ, Wang P, Xia HM, Qiu X, Muglia LJ. Ambient temperature and the risk of preterm birth in Guangzhou, China (2001-2011). Environ Health Persp. 2016:124(7):1100-6.

30. Fleischer NL, Merialdi M, van Donkelaar A, Vadillo-Ortega F, Martin RV, Betran AP, Souza JP, O'Neill MS. Outdoor air pollution, preterm birth, and low birth weight: analysis of the world health organization global survey on maternal and perinatal health. Environ Health Persp. 2014;4:425-30.

31. Parker JD, Woodruff TJ. Influences of study design and location on the relationship between particulate matter air pollution and birthweight. Paediatr Perinat Ep. 2008;22(3):214-27.

32. Morello-Frosch R, Shenassa ED. The environmental "riskscape" and social inequality: implications for explaining maternal and child health disparities. Environ Health Persp. 2006;114(8):1150-3.

33. Padula AM, Huang HT, Baer RJ, August LM, Jankowska MM, JellifePawlowski LL, Sirota M, Woodruff TJ. Environmental pollution and social factors as contributors to preterm birth in Fresno County. Environ Health Glob. 2018;17(8):70.

34. Apergis N, Ozturk I. Testing Environmental Kuznets Curve hypothesis in Asian countries. Ecol Indic. 2015;52:16-22.

35. Arcury TA, Preisser JS, Gesler WM, Powers JM. Access to transportation and health care utilization in a rural region. J Rural Health. 2005;21(1):31-8.

36. Fotso JC. Urban-rural differentials in child malnutrition: trends and socioeconomic correlates in sub-Saharan Africa. Health Place. 2007;13(1):205-23.

37. Liu H, Fang $H$, Zhao Z. Urban-rural disparities of child health and nutritional status in China from 1989 to 2006. Econ Hum Biol. 2013;11(3):294-309.

38. Dwyer M, Rehman S, Ottavi T, Stankovich J, Gall S, Peterson G, Ford K, Kinsman L. Urban-rural differences in the care and outcomes of acute stroke patients: systematic review. J Neurol Sci. 2019;397:63-74.

39. Weaver KE, Palmer N, Lu LY, Case LD, Geiger AM. Rural-urban differences in health behaviors and implications for health status among US cancer survivors. Cancer Cause Control. 2013;24(8):1481-90.

40. Song Q, Smith JP. Hukou system, mechanisms, and health stratification across the life course in rural and urban China. Health Place. 2019:58:102150.

41. Bigbee JL, Musil C, Kenski D. The health of caregiving grandmothers: a rural-urban comparison. J Rural Health. 2011;27(3):289-96.

42. Bertin M, Chevrier C, Serrano T, Monfort C, Rouget F, Cordier S, Viel JF. Association between prenatal exposure to traffic-related air pollution and preterm birth in the PELAGIE mother-child cohort, Brittany, France. Does the urban-rural context matter? Environ Res. 2015:142:17-24.

43. Hu KJ, Guo YT, Hoehrainer-Stigler S, Liu W, See L, Yang XC, Zhong JM, Fei FR, Chen F, Zhang YQ, Zhao Q, Chen GB, Chen Q, Zhang YZ, Ye TT, Ma L, Li SS, Qi JG. Evidence for urban-rural disparity in temperaturemortality relationships in Zhejiang Province, China. Environ Health Persp. 2019;127(3):037001

44. Eberhardt MS, Pamuk ER. The importance of place of residence: examining health in rural and nonrural areas. Am J Public Health. 2004;94(10):1682-6.

45. McLafferty S, Wang FH. Rural reversal? Rural-urban disparities in late-stage cancer risk in Illinois. Cancer. 2009;115(12):2755-64.

46. Cohen SA, Cook SK, Sando TA, Sabik NJ. What aspects of rural life contribute to rural-urban health disparities in older adults? Evidence from a national survey. J Rural Health. 2018;34(3):293-303.

47. Larson EH, Hart LG, Rosenblatt RA. Is non-metropolitan residence a risk factor for poor birth outcome in the US? Soc Sci Med. 1997;45(2):171-88.

48. Hulme PA, Blegen MA. Residential status and birth outcomes: is the rural urban distinction adequate? Public Health Nurs. 1999;16(3):176-81. 
49. Hillemeier MM, Weisman CS, Chase GA, Dyer AM. Individual and community predictors of preterm birth and low birthweight along the ruralurban continuum in central Pennsylvania. J Rural Health. 2007;23(1):42-8.

50. The Central People's Government of the People's Republic of China. 2018. http://www.gov.cn/guoqing/2018-01/17/content_5257425.htm. Accessed 10 Sept 2019.

51. Grell GA, Peckham SE, Schmitz R, McKeen SA, Frost G, Skamarock WC, Eder B. Fully coupled "online" chemistry within the WRF model. Atmos Environ. 2005:39(12):6957-75.

52. Shen HZ, Tao S, Chen YL, Ciais P, Guneralp B, Ru MY, Zhong QR, Yun X, Zhu X, Huang TB, Tao W, Chen YC, Li BG, Wang XL, Liu WX, Liu JF, Zhao SQ. Urbanization-induced population migration has reduced ambient $\mathrm{PM}_{2.5}$ concentrations in China. Sci Adv. 2017:3(7):e1700300.

53. You SM, Tong YW, Neoh KG, Dai YJ, Wang CH. On the association between outdoor PM2.5 concentration and the seasonality of tuberculosis for Beijing and Hong Kong. Environ Pollut. 2016;218:1170-9.

54. . Hubei Provincial Bureau of Statistics. http://tjj.hubei.gov.cn/tjsj/. Accessed 12 Apr 2020

55. China National Bureau of Statistics. Provisions on the statistical division of urban and rural areas (Trial). http://www.stats.gov.cn/tjsj/ndsj/renko upucha/2000pucha/html/append7.htm. Accessed 10 Sept 2019.

56. Moran PAP. Notes on continuous stochastic phenomena. Biometrika. 1950;37(6):17-23.

57. Cliff AD, Ord JK. Spatial processes: models \& applications. London: Pion Limited; 1981

58. Wartenberg D. Multivariate spatial correlation: a method for exploratory geographical analysis. Geogr Anal. 1985;17:263-83.

59. Anselin L, Syabri I, Smirnov O. Visualizing multivariate spatial correlation with dynamically linked windows. http://www.real.illinois.edu/d-paper /02/02-t-8.pdf. Accessed 10 Sept 2019.

60. Wang FH, Guo DS, McLafferty S. Constructing geographic areas for cancer data analysis: a case study on late-stage breast cancer risk in Illinois. Appl Geogr. 2012;35(11):1-11.

61. Talbot TO, Kulldorff M, Forand SP, Haley VB. Evaluation of spatial filters to create smoothed maps of health data. Stat Med. 2000;19(9):2399-408.

62. Anselin L. Local indicators of spatial association-LISA. Geogr Anal. 1995;27(2):93-115.

63. Anselin L, Syabri I, Kho Y. GeoDa: an introduction to spatial data analysis. Geogr Anal. 2006;38(1):5-22.

64. Bates D, Machler M, Bolker BM, Walker SC. Fitting linear mixed-effects models using Ime4. J Stat Softw. 2015;67(1):1-48.

65. Wang JF, Li XH, Christakos G, Liao YL, Zhang T, Gu X, Zheng XY. Geographical detectors-based health risk assessment and its application in the neural tube defects study of the Heshun region, China. Int J Geogr Inf Sci. 2010;24(1):107-27.

66. Wang JF, Zhang TL, Fu BJ. A measure of spatial stratified heterogeneity. Ecol Indic. 2016;67(8):250-6.

67. van Donkelaar A, Martin RV, Kahn BMR, Levy R, Verduzco C, Villeneuve PJ. Global estimates of ambient fine particulate matter concentrations from satellite-based aerosol optical depth: development and application. Environ Health Persp. 2010;118(6):847-55.

68. Pereira G, Belanger K, Bell M. A longitudinal study of fine particulates and risk of preterm birth in connecticut 2000-2006. Am J Epidemiol. 2013;177(S156-S156):11.
69. Raaschou-Nielsen O, Andersen ZJ, Beelen R, Samoli E, Stafoggia M, Weinmayr G, Hoffmann B, Fischer P, Nieuwenhuijsen MJ, Brunekreef B, Xun WW, Katsouyanni K, Dimakopoulou K, Sommar J, Forsberg B, Modig L, Oudin A, Oftedal B, Schwarze PE, Nafstad P, De Faire U, Pedersen NL, Ostenson CG, Fratiglioni L, Penell J, Korek M, Pershagen G, Eriksen KT, Sorensen M, Tjonneland A, Ellermann T, Eeftens M, Peeters PH, Meliefste K, Wang M, Bueno-de-Mesquita B, Key TJ, de Hoogh K, Concin H, Nagel G, Vilier A, Grioni S, Krogh V, Tsai MY, Ricceri F, Sacerdote C, Galassi C, Migliore E, Ranzi A, Cesaroni G, Badaloni C, Forastiere F, Tamayo I, Amiano P, Dorronsoro M, Trichopoulou A, Bamia C, Vineis P, Hoek G. Air pollution and lung cancer incidence in 17 European cohorts: prospective analyses from the European Study of Cohorts for Air Pollution Effects (ESCAPE). Lancet Oncol. 2013;14(9):813-22.

70. Guo P, Miao HZ, Chen YL, Fu Y, Wu YT, Zhao QG, Li B. Maternal exposure to gaseous ambient air pollutants increases the risk of preterm birth in the Pearl River Delta, China 2014-2017. Sci Total Environ. 2019;671:959-70.

71. Wang Q, Li B, Benmarhnia T, Hajat S, Ren M, Liu T, Knibbs LD, Zhang HH, Bao JZ, Zhang YW, Zhao QG, Huang CR. Independent and combined effects of heatwaves and PM2.5 on preterm birth in Guangzhou, China: a survival analysis. Environ Health Persp. 2020;128(1):017006.

72. Lee BE, Ha EH, Park HS, Kim YJ, Hong YC, Kim H, Lee JT. Exposure to air pollution during different gestational phases contributes to risks of low birth weight. Hum Reprod. 2003;18(3):638-43.

73. Bobak M. Outdoor air pollution, low birth weight, and prematurity. Environ Health Persp. 2000;108(2):173-6.

74. Llop S, Ballester F, Estarlich M, Esplugues A, Rebagliato M, Iniguez C. Preterm birth and exposure to air pollutants during pregnancy. Environ Res. 2010;110(8):778-85.

75. National Development and Reform Commission. 2017. http://www.ndrc gov.cn/zcfb/zcfbtz/201701/t20170125_836739.html. Accessed 10 Sept 2019.

76. Yang Y, Liang ZJ, Ruan ZL, Zhang SY, Zhao QG, Lin HL. Estimating the attributable burden of preterm birth and low birth weight due to maternal ozone exposure in nine Chinese cities. Atmos Environ. 2020;222:117169.

77. Strand LB, Barnett AG, Tong SL. Maternal exposure to ambient temperature and the risks of preterm birth and stillbirth in Brisbane, Australia. Am J Epidemiol. 2012;175(2):99-107.

78. Vicedo-Cabrera AM, Iniguez C, Barona C, Ballester F. Exposure to elevated temperatures and risk of preterm birth in Valencia, Spain. Environ Res. 2014;134:210-7.

79. Sun SZ, Spangler KR, Weinberger KR, Yanosky JD, Braun JM, Wellenius GA. Ambient temperature and markers of fetal growth: a retrospective observational study of 29 million US singleton births. Environ Health Persp. 2019;127(6):067005.

\section{Publisher's Note}

Springer Nature remains neutral with regard to jurisdictional claims in published maps and institutional affiliations.

\footnotetext{
Ready to submit your research? Choose BMC and benefit from:

- fast, convenient online submission

- thorough peer review by experienced researchers in your field

- rapid publication on acceptance

- support for research data, including large and complex data types

- gold Open Access which fosters wider collaboration and increased citations

- maximum visibility for your research: over 100M website views per year
}

At BMC, research is always in progress.

Learn more biomedcentral.com/submissions 